\title{
Combined oxidative phosphorylation defect type 13
}

INSERM

\section{Source}

INSERM. (1999). Orphanet: an online rare disease and orphan drug data base. Combined oxidative phosphorylation defect type 13. ORPHA:319514

Combined oxidative phosphorylation defect type 13 is a rare mitochondrial disease due to a defect in mitochondrial protein synthesis characterized by normal early development followed by the sudden onset in infancy of poor feeding, dysphagia, truncal (followed by global) hypotonia, motor regression, abnormal movements (i.e. severe dystonia of limbs, choreoathetosis, facial dyskinesias) and reduced tendon reflexes. The disease course is severe but nonprogressive. 